\title{
Introduction
}

\section{Michel Berré}

\section{(2) OpenEdition \\ Journals}

Édition électronique

URL : https://journals.openedition.org/dhfles/132

DOI : $10.4000 /$ dhfles. 132

ISSN : 2221-4038

\section{Éditeur}

Société Internationale pour l'Histoire du Français Langue Étrangère ou Seconde

Édition imprimée

Date de publication : 1 janvier 2007

Pagination : 5-7

ISSN : 0992-7654

Référence électronique

Michel Berré, «Introduction », Documents pour l'histoire du français langue étrangère ou seconde [En ligne], 38/39 | 2007, mis en ligne le 28 novembre 2010, consulté le 27 mai 2021. URL : http:// journals.openedition.org/dhfles/132; DOI : https://doi.org/10.4000/dhfles.132

Ce document a été généré automatiquement le 27 mai 2021

(c) SIHFLES 


\title{
Introduction
}

\author{
Michel Berré
}

1 Ce numéro de Documents pour l'histoire du français langue étrangère ou seconde présente les actes du premier colloque organisé par la SIHFLES (Société internationale pour l'histoire du français langue étrangère ou seconde) en Turquie, plus précisément à Istanbul, à l'université Galatasaray, où près d'une centaine de spécialistes de l'histoire de la diffusion et de l'enseignement des langues se sont réunis du 7 au 9 novembre 2006.

2 Selon l'article 2 de ses statuts, la SIHFLES a pour objectif de «[...] promouvoir l'histoire de l'enseignement et de la diffusion du français langue étrangère ou langue seconde hors de France et en France et, d'une manière générale, de la didactique des langues...». Un tel objectif ne pouvait qu'entrainer une grande diversité des questionnements et des objets de recherche depuis la création de la Société en décembre 1987. Les sept colloques internationaux organisés en moins de 10 ans par la SIHFLES, entre 1998 et 2006, témoignent de cette multiplicité des centres d'intérêt et de la nécessaire diversité des points de vue pour rendre compte d'un objet aussi complexe et protéiforme que la diffusion et l'enseignement d'une langue. À Sintra (Portugal) en 1998, la question de l'enseignement du français fut abordée sous l'angle de la littérature: quelle place pour l'enseignement littéraire en pleine mutation dans la seconde moitié du XIX ${ }^{e}$ siècle dans ses relations avec l'enseignement / apprentissage de la langue ? Un an plus tard, à Utrecht (Pays-Bas), l'histoire de l'enseignement est traitée en relation avec le statut de la langue française et les changements politiques qui affectent l'histoire européenne de la fin du $\mathrm{XVIII}^{\mathrm{e}}$ siècle au milieu du $\mathrm{XX}^{\mathrm{e}}$ siècle. Palerme, en 2001, voit affluer des quatre coins de la Méditerranée des chercheurs soucieux de poser les premiers jalons d'une réflexion d'ensemble sur la diffusion du français dans la bassin méditerranéen. Deux ans plus tard, la SIHFLES réunit, à Bologne, didacticiens, spécialistes de l'enseignement littérature, mais aussi philosophes et historiens de l'éducation pour une rencontre centrée sur le destin exceptionnel du Télémaque de Fénelon; puis c'est Valence (Espagne) où est posée la question de l'impact de l'institutionnalisation des langues étrangères et de la professionnalisation du métier d'enseignant sur la manière de concevoir et de pratiquer l'enseignement du français. Vient ensuite Lyon (décembre 2005) et l'histoire du Français fondamental (1954), 
élargie à la place des vocabulaires de base et de l'oral dans la didactique des langues étrangères depuis l'après-guerre... Et enfin, Istanbul (novembre 2006) qui reprend la question de la diffusion du français dans le bassin méditerranéen en la mettant plus précisément en relation avec un groupe socioculturel donné - les «élites» - et en élargissant le cadre géographique à la péninsule balkanique.

De cette intense activité scientifique, l'on pouvait craindre qu'elle ne provoque un certain essoufflement ou ne soit un signe d'éparpillement. Il n'en a rien été. Plus de soixante intervenants étaient présents à Istanbul et ont montré - ainsi qu'en témoigne le présent volume dont le contenu est résumé dans l'introduction du professeur Osman Senemoğlu ${ }^{1}$ - la capacité de la SIHFLES à réunir un important public de spécialistes soucieux d'aborder de manière interdisciplinaire des questions peu traitées jusqu'ici. Quant à la diversité des objets, elle n'empêche pas une grande convergence dans le positionnement de la Société qui, depuis sa création, a puissamment contribué à la spécialisation du champ de recherches en mettant à la disposition des chercheurs, des lieux de rencontre et des supports de publication permettant l'accumulation et l'échange des savoirs sans lesquels il ne peut y avoir de développement scientifique.

4 Toute rencontre est un événement et il ne peut y avoir d'événement sans qu'il y ait des hommes qui les suscitent, les organisent et les vivent. En tant que président de la SIHFLES, je remercie toutes les personnes - et tout d'abord les intervenants - qui ont contribué à la réussite du colloque d'Istanbul. Je suis particulièrement reconnaissant au professeur Osman Senemoğlu qui a répondu avec ferveur à notre appel et a mis à la disposition de la Société non seulement ses connaissances relatives à l'objet étudié, mais aussi son temps, son énergie, son hospitalité pour faire de cette rencontre scientifique une magnifique rencontre humaine. Avec lui, c'est aussi une équipe et une institution qu'il convient de remercier, à savoir Monsieur le Professeur Duygun Yarsuvat, président de l'université Galatasaray, Monsieur le Professeur Kenan Gürsoy, doyen de la Faculté des Sciences et Lettres, les enseignants du Département de linguistique comparée ainsi que MM. Atilla Demircioglu, Engin Bezci et Mme şilan Evirgen.

5 Enfin, ma gratitude va à Henri Besse, Gisèle Kahn et Nadia Minerva qui ont accepté la patiente et épineuse tâche de la révision de l'ensemble des textes ainsi que leur correction finale et leur mise en page.

\section{NOTES}

1. Dix-sept communications ont pu être reprises dans les actes. Les autres interventions feront l'objet d'une autre publication. Nous prions les auteurs de bien vouloir excuser les organisateurs pour le retard pris dans la réalisation de ce volume. 


\section{AUTEUR}

MICHEL BERRÉ

Président de la SIHFLES, Université de Mons (Belgique) 